\title{
INVESTIGATION OF THE FATTY ACID COMPOSITION OF THE SNAIL SUCCINEA PUTRIS L.
}

\author{
D. J. VAN DER HORST and P. A. VOOGT \\ Laboratory of Chemical Animal Physiology, University of Utrecht
}

(Received 18 April 1969)

\begin{abstract}
The incorporation of $1-{ }^{14} \mathrm{C}$-acetate into some classes of lipids by Succinea putris $\mathrm{L}$. is investigated.

2. This snail is able to synthesize fatty acids from injected acetate.

3. The acetate is also used for the synthesis of non-saponifiable lipids.

4. The fatty acid composition of these animals is discussed.
\end{abstract}

\section{INTRODUCTION}

IN THE last few years there have been many investigations concerning the lipids present in molluscs. So the occurrence and distribution of $3 \beta$-sterols in this phylum have been studied extensively. The known data have been summarized by Bergmann (1962). The presence or absence of sterol biosynthesis has been examined in several species (Fagerlund \& Idler, 1960; Salaque et al., 1966; Voogt, 1967a, b, 1968a, b, 1969; Zandee, 1967).

In contrast to this, little is known about the composition of fatty acids in this group of animals. Venugopalan (1966) reports some differences in the fatty acid composition of the two sexes of the oyster Crassostrea madrasensis, and Gruger et al. (1964) studied the occurrence of fatty acids in some marine shellfishes. This paper deals with the fatty acid composition of a land snail, Succinea putris L., belonging to the order Stylommatophora (Mollusca, Gastropoda, Pulmonata).

\section{MATERIALS AND METHODS}

Snails of the species Succinea putris L. were collected in June 1968 in the neighbourhood of the laboratory at Utrecht. Four hundred animals (fresh wt., without shells, $53 \mathrm{~g}$ ) were injected with $0.01 \mathrm{ml}$ of an aqueous solution of sodium-1-14 $\mathrm{C}$-acetate (specific activity: $20 \mathrm{mc} / \mathrm{m}$-mol, Philips Duphar) into the hepatopancreas. The total dose administered was $100 \mu \mathrm{c}$. Ninety-three very small animals (fresh wt. $7 \mathrm{~g}$ ) of the same species were used as a supplement to the material. Incubation lasted for $48 \mathrm{hr}$.

Lipids were extracted from the animals according to the method of Bligh \& Dyer (1959) and saponified by refluxing them with a solution of $1.5 \mathrm{~N} \mathrm{KOH}$ in $80 \%$ methanol, for $6 \mathrm{hr}$ at $65^{\circ} \mathrm{C}$ in an atmosphere of nitrogen.

The non-saponifiable lipids were obtained by extracting them from the water-diluted saponification mixture with petroleum ether (b.p. $40-60^{\circ} \mathrm{C}$ ). The residue was acidified with concentrated hydrochloric acid to $\mathrm{pH} 1$ after which the fatty acids were isolated by extracting the mixture with petroleum ether (b.p. $40-60^{\circ} \mathrm{C}$ ). The two petroleum ether fractions thus obtained were washed with water and filtered over anhydrous sodium sulphate and, in case of the fatty acids, decolorized with acid-washed activated charcoal. 
The charcoal was filtered off and washed with ether. By combining the ether filtrate with the petroleum ether fraction a high yield of fatty acids was obtained.

Samples of the fatty acids were methylated (Schlenk \& Gellerman, 1960). In order to obtain a better insight into the fatty acid composition of $S$. putris two different separatory techniques preceding gas-liquid chromatography were applied.

1. A separation of the methyl esters of saturated and unsaturated fatty acids on a column with silicic acid (Mallinckrodt, 100 mesh), preceded by mercury addition to the unsaturated fatty acids (Goldfine \& Bloch, 1961).

2. A separation on thin-later plates (Kieselgel G, Merck) of methyl esters of saturated and unsaturated fatty acids (White $\&$ Williams, 1965; White, 1966). With this method, which also depends on mercury addition to the unsaturated fatty acids, it is possible to determine the number of double bonds present in the various fatty acids.

Samples of the total fatty acids, and of the unsaturated ones, derived from both column and thin-layer plates, were hydrogenated according to Farquhar et al. (1959).

Gas chromatography of the methylated fatty acids was performed on a Becker Unigraph F, equipped with flame ionization detection. The column used (aluminium, $1.50 \mathrm{~m} \times$ $3.8 \mathrm{~mm}$ i.d.) was packed with acid- and alkaline-washed Chromosorb W, 60-80 mesh, coated with $20 \%$ PEGA and $2 \%$ phosphoric acid. The temperature of the column was $184^{\circ} \mathrm{C}$, that of the injection point $215^{\circ} \mathrm{C}$. The flow of the carrier gas $\left(\mathrm{N}_{2}\right)$ was $50 \mathrm{ml} / \mathrm{min}$.

All radioactivities were measured in toluene-PPO-POPOP (Hayes et al., 1956) with a Packard Tri-Carb Liquid Scintillation Spectrometer, Model 3315, equipped with an automatic external standardization. Radioactivity of thin-layer chromatograms was determined with a Berthold automatic, two-dimensional Chromatography Scanner, type LB 2721.

\section{RESULTS}

The quantities of the isolated lipid fractions and components are summarized in Table 1.

Table 1.-Quantities of Isolated lipid fractions and components From $S$. putris

\begin{tabular}{lcc}
\hline \multicolumn{1}{c}{ Lipid fraction } & Wt. (mg) & $\%$ of the fresh wt. \\
\hline Fresh wt. & 60,000 & \\
Total lipids & $870 \cdot 5$ & $1 \cdot 45$ \\
Non-saponifiable fraction & $70 \cdot 3$ & $0 \cdot 12$ \\
Fatty acids & $252 \cdot 7$ & $0 \cdot 42$ \\
\hline
\end{tabular}

The radioactivity of the various lipid fractions is summarized in Table 2.

The results of gas chromatography of the saturated fatty acids (obtained after Goldfine \& Bloch, 1961) are summarized in Table 3.

The unsaturated fatty acids, obtained as described before, are listed in Table 4.

The separation of fatty acids on thin-layer chromatograms after White \& Williams (1965) turned out to be a very useful method for identifying the unsaturated fatty acids, and ensured greater certainty for the classification. After 
colouring with iodine, the thin-layer chromatograms showed three dark-coloured bands, which were sharply separated from each other by colourless ones.

Band $1\left(R_{f}: 0 \cdot 66\right)$ contained the saturated fatty acids.

Band $2\left(R_{f} 0.57\right)$ contained the mono-unsaturated fatty acids.

Band $3\left(R_{f}: 0.52\right)$ contained the di-unsaturated fatty acids.

Band 4 (not coloured) contained the poly-unsaturated fatty acids.

TABLE 2-TOTAL AND SPECIFIC RADIOACTIVITY OF THE ISOLATED LIPID FRACTIONS FROM S. putris, AFTER ADMINISTRATION OF SODIUM-1- ${ }^{14} \mathrm{C}$-ACETATE

\begin{tabular}{lcr}
\hline \multicolumn{1}{c}{ Lipid fraction } & $\mathrm{dpm} / \mathrm{mg}$ & $\begin{array}{c}\text { Total activity } \\
(\mathrm{dpm})\end{array}$ \\
\hline Total lipids & $1844 \cdot 2$ & $1,605,376 \cdot 1$ \\
Non-saponifiable fraction & $1674 \cdot 2$ & $117,696 \cdot 3$ \\
Fatty acids & $2748 \cdot 9$ & $694,647 \cdot 0$ \\
\hline
\end{tabular}

TABLE 3-THE PROPORTIONAL COMPOSITION OF THE FRACTION CONTAINING THE SATURATED FATTY ACIDS OF S. putris

\begin{tabular}{|c|c|c|c|c|c|}
\hline $\mathrm{RRT}^{*}$ & Name ${ }^{\dagger}$ & $\% \ddagger$ & $\mathrm{RRT}^{*}$ & Name $\dagger$ & $\% \pm$ \\
\hline - & - & $1.94 \S$ & $1 \cdot 3651$ & $19: 0$ & $1 \cdot 58$ \\
\hline $0 \cdot 2141$ & $14: 0$ iso & 0.09 & 1.5319 & $20: 0$ iso & 0.66 \\
\hline $0 \cdot 2355$ & 14:0 ante-iso & $0 \cdot 19$ & 1.7335 & 20:0 ante-iso & 0.06 \\
\hline 0.2666 & $14: 0$ & 2.03 & $1: 9219$ & $20: 0$ & 0.25 \\
\hline $0 \cdot 2912$ & $15: 0$ iso & $2 \cdot 08$ & $2 \cdot 1386$ & $21: 0$ iso & 0.56 \\
\hline $0 \cdot 3662$ & $15: 0$ & 1.69 & $2 \cdot 4095$ & 21:0 ante-iso & 0.40 \\
\hline $0 \cdot 4133$ & $16: 0$ iso & $2 \cdot 23$ & 2.6555 & $21: 0$ & $0 \cdot 18$ \\
\hline $0 \cdot 5139$ & $16: 0$ & $32 \cdot 36$ & 2.9555 & $22 \cdot 0$ iso & $0 \cdot 20$ \\
\hline $0 \cdot 5664$ & $17: 0$ iso & $5 \cdot 39$ & $3 \cdot 3672$ & $22: 0$ ante-iso & $0 \cdot 22$ \\
\hline $0 \cdot 6510$ & $17: 0$ ante-iso & $4 \cdot 22$ & $3 \cdot 7270$ & $22: 0$ & $0 \cdot 24$ \\
\hline $0 \cdot 7184$ & $17: 0$ & $3 \cdot 80$ & $4 \cdot 2925$ & $23: 0$ iso & Trace \\
\hline $0 \cdot 8019$ & $18: 0$ iso & 1.64 & $4 \cdot 7042$ & 23:0 ante-iso & Trace \\
\hline $1 \cdot 0000$ & 18:0 & $30 \cdot 23$ & $5 \cdot 2362$ & $23: 0$ & Trace \\
\hline $1 \cdot 1156$ & $19: 0$ iso & $5 \cdot 27$ & 6.5157 & 24:0 ante-iso & $0 \cdot 21$ \\
\hline $1 \cdot 2524$ & 19:0 ante-iso & $2 \cdot 23$ & $7 \cdot 1744$ & $24: 0$ & 0.07 \\
\hline
\end{tabular}

* The relative retention time (RRT) of stearic acid $(18: 0)=1 \cdot 0000$.

$\dagger$ Short-hand designation.

$\ddagger$ Percentages are the mean values of four chromatograms.

$\$$ Percentage of the fatty acids before 14:0 iso.

The radioactivity of these thin-layer chromatograms was measured. The saturated, mono- and di-unsaturated fatty acids were distinctly labelled. Gas chromatography of the fatty acids, obtained from the various bands, provided a 
supplement to the unsaturated fatty acids, given in Table 4. This supplement, in which only trace amounts are concerned, is listed in Table 5.

TABLE 4 - THE PROPORTIONAL COMPOSITION OF THE FRACTION WITH THE UNSATURATED FATTY ACIDS of $S$. putris

\begin{tabular}{|c|c|c|c|c|c|}
\hline RRT* & Name $\dagger$ & $\%$ & $\mathrm{RRT}^{*}$ & Namet & $\%$ \\
\hline- & - & $1.63 \ddagger$ & 0.9678 & $17: 2$ & 0.34 \\
\hline $0 \cdot 2901$ & $14: 1$ & $0 \cdot 14$ & $1 \cdot 1006$ & $18: 1$ & 41.06 \\
\hline 0.3094 & $13: 3$ & 0.16 & $1 \cdot 3340$ & $18: 2$ & $16 \cdot 87$ \\
\hline 0.3555 & $14: 2$ & 0.09 & 1.5128 & $19: 1$ & $1 \cdot 20$ \\
\hline 0.4004 & $15: 1$ & 0.60 & $1 \cdot 7281$ & $18: 3$ & 6.62 \\
\hline 0.4358 & $14: 3$ & 0.44 & 2.0728 & $20: 1$ & $4 \cdot 13$ \\
\hline 0.5000 & $15: 2$ & 0.37 & $2 \cdot 2645$ & $19: 3$ & 1.85 \\
\hline 0.5546 & $16: 1$ & $4 \cdot 46$ & 2.5493 & $20: 2$ & 5.96 \\
\hline 0.5771 & $16: 1$ & 4.08 & $3 \cdot 2120$ & $20: 3$ & 4.97 \\
\hline 0.6959 & $16: 2$ & 0.27 & 5.0193 & $22: 2$ & 0.64 \\
\hline 0.7848 & $17: 1$ & $2 \cdot 01$ & $6 \cdot 1627$ & $22: 3$ & $1 \cdot 34$ \\
\hline
\end{tabular}

* RRT are based on: RRT stearic acid $=1.0000$.

$\uparrow$ Short-hand designation.

$\ddagger$ Percentage of the unsaturated fatty acids before 14:1.

Table 5-Supplement of the fatty acids given in Table 4 after separation of unSATURATED FATTY ACIDS ON THIN-LAYER PLATES

\begin{tabular}{|c|c|c|c|}
\hline $\mathbf{R R T}^{*}$ & Name $\dagger$ & $\mathrm{RRT}^{*}$ & Name $\dagger$ \\
\hline 0.6216 & $15: 3$ & 3.0076 & $19: 4$ \\
\hline 0.8953 & $16: 3$ & 3.9488 & $20: 4$ \\
\hline $1 \cdot 2345$ & $17: 3$ & $4 \cdot 2312$ & $20: 4$ \\
\hline 1.8550 & $19: 2$ & $4 \cdot 3075$ & $?: 2$ \\
\hline $2 \cdot 1308$ & $?: 2$ & $4 \cdot 7001$ & $21: 3$ \\
\hline $2 \cdot 1919$ & $18: 4$ & $7 \cdot 4656$ & $22: 4$ \\
\hline 2.9771 & $?: 2$ & $12 \cdot 5954$ & $24: 3$ \\
\hline
\end{tabular}

* RR'T are based on: RRT stearic acid $=1 \cdot 0000$.

$\dagger$ Short-hand designation.

The fraction of unsaturated fatty acids obtained after column chromatography was hydrogenated (Farquhar et al., 1959) for $6 \mathrm{hr}$. Gas chromatograms of this fraction showed not only the expected saturated $n$-homologues (C-14 to C-24), but also traces of branched-chain fatty acids: 18:0 iso, 18:0 ante-iso, 19:0 ante-iso, 21:0 ante-iso, 22:0 iso, 22:0 ante-iso, 23:0 ante-iso, 24:0 ante-iso and, possibly, 25:0 ante-iso.

The sample was hydrogenated again for $6 \mathrm{hr}$, but no change of the fatty acid composition could be observed. This result is an indication for the presence of branched-chain unsaturated fatty acids. The unknown di-unsaturated fatty acids 
in Table 5 could point in the same direction, though more evidence will be necessary to establish this point.

The total fatty acid composition of $S$. putris is summarized in Table 6 . The proportional composition of the total fatty acids is calculated for the saturated and unsaturated column fractions, by adjusting the height of 18:0 and 18:1 in chromatograms of the saturated and unsaturated fractions respectively, on the height of these peaks in chromatograms of the total fatty acids (after eliminating the influence of 19:0 iso in these chromatograms). In this way correction factors are obtained for the height of all peaks in both fractions.

Table 6-Proportional composition of the fatty acids of $S$. putris calculated from THE RESUlTS SHOWN IN TABLES 3, 4 and 5

\begin{tabular}{|c|c|c|c|}
\hline Name* & $\%$ & Name* & $\%$ \\
\hline $14: 0$ iso & 0.05 & 19:1 & 0.53 \\
\hline $13: 1$ & 0.06 & $20: 0$ iso & 0.36 \\
\hline 14:0 ante-iso & 0.10 & $18: 3$ & 2.91 \\
\hline $12: 3$ & 0.13 & 20:0 ante-iso & 0.03 \\
\hline $14: 0$ & $1 \cdot 12$ & $19: 2$ & Trace \\
\hline $13: 2$ & Trace & $20: 0$ & $0 \cdot 14$ \\
\hline 14:1 & 0.06 & $20: 1$ & 1.81 \\
\hline $15: 0$ iso & $1 \cdot 15$ & $?: 2$ & Trace \\
\hline $13: 3$ & 0.07 & $21: 0$ iso & $0 \cdot 31$ \\
\hline $14: 2$ & 0.04 & $18: 4$ & Trace \\
\hline $15: 0$ & 0.94 & $19: 3$ & $0 \cdot 81$ \\
\hline 15:1 & $0 \cdot 26$ & 21:0 ante-iso & 0.22 \\
\hline $16: 0$ iso & $1 \cdot 24$ & $20: 2$ & $2 \cdot 61$ \\
\hline $14: 3$ & $0 \cdot 20$ & 21:0 & $0 \cdot 10$ \\
\hline $15: 2$ & $0 \cdot 16$ & $22: 0$ iso & $0 \cdot 11$ \\
\hline $16: 0$ & $17 \cdot 96$ & ?:2 & Trace \\
\hline $16: 1$ & 1.96 & $19: 4$ & Trace \\
\hline $17: 0$ iso & $2: 99$ & $20: 3$ & $2 \cdot 18$ \\
\hline $16: 1$ & $1 \cdot 79$ & 22:0 ante-iso & $0 \cdot 12$ \\
\hline $15: 3$ & Trace & $22: 0$ & 0.13 \\
\hline $17: 0$ ante-iso & $2 \cdot 33$ & $20: 4$ & Trace \\
\hline $16: 2$ & 0.12 & $20: 4$ & Trace \\
\hline $17: 0$ & $2 \cdot 11$ & $23: 0$ iso & Trace \\
\hline $17: 1$ & $0 \cdot 88$ & $?: 2$ & Trace \\
\hline $18: 0$ iso & 0.91 & $21: 3$ & Trace \\
\hline $16: 3$ & Trace & 23:0 ante-iso & Trace \\
\hline $17: 2$ & $0 \cdot 15$ & $22: 2$ & $0 \cdot 22$ \\
\hline $18: 0$ & $16 \cdot 78$ & 23:0 & Trace \\
\hline $18: 1$ & $18 \cdot 01$ & $22: 3$ & 0.59 \\
\hline $19: 0$ iso & $2 \cdot 92$ & 24:0 ante-iso & $0 \cdot 12$ \\
\hline $17: 3$ & Trace & $24: 0$ & $0 \cdot 04$ \\
\hline $19: 0$ ante-iso & 1.24 & $22: 4$ & Trace \\
\hline $18: 2$ & $7 \cdot 40$ & $24: 3$ & Trace \\
\hline $19: 0$ & 0.88 & & \\
\hline
\end{tabular}

* Short-hand designation. 


\section{DISCUSSION}

Table 2 shows that the isolated lipid fractions of $S$. putris possess a high specific radioactivity. This means that the injected acetate has been used for the biosynthesis of these lipids. Specially the fatty acids are highly labelled. On thin-layer chromatograms the saturated mono- and di-unsaturated fatty acids are distinctly radioactive. The composition of the fatty acid fraction has been determined by means of gas-liquid chromatography. First the usual procedure was followed. Gas chromatograms of the total fatty acid fraction before and after hydrogenation were compared to decide which of the peaks in the "total" chromatogram belonged to unsaturated fatty acids and which to saturated ones. Identification in this way is only possible if hydrogenation is complete. However, there were indications that the latter was not always the case. Further, in the total chromatograms only a relatively small number of fatty acids could be distinguished. That is why the fatty acids were separated into saturated and unsaturated ones prior to gas chromatography following the procedure of Goldfine \& Bloch (1961). This separation is, as far as could be observed, complete. Therefore the method is suitable for quantitative calculations. The separation of fatty acids on thin-layer plates, though not complete, provided a good indication for the classification of the unsaturated fatty acids. The application of these two separatory techniques prior to gas chromatography yielded a number of fatty acids which was about twice that obtained in the conventional way. For these reasons it is of advantage to combine the methods of thin-layer, column and gas-liquid chromatography for the identification of fatty acids.

The total fatty acid composition of $S$. putris could be divided as follows: 55.5 per cent of the fatty acids is saturated, while 43.8 per cent is not. The saturated fatty acid fraction can be divided into: normal straight-chain fatty acids, 73.2 per cent; branched-chain fatty acids, 18.3 per cent iso, $7 \cdot 8$ per cent ante-iso. The unsaturated fatty acids consist of the following groups: mono-unsaturated fatty acids, 58.1 per cent; di-unsaturated fatty acids, 24.6 per cent; tri-unsaturated fatty acids, 15.7 per cent; tetra-unsaturated fatty acids, traces.

There were some indications for the presence of trace amounts of branchedchain unsaturated fatty acids, iso as well as ante-iso, in $S$. putris, but further investigations on the structure of these components will be necessary. It should be noted that large amounts of branched-chain unsaturated fatty acids have been reported for a fresh-water fish, Scardinius erythrophtalmus L. (Saxena \& Zandee, 1968).

Neither the biosynthesis of the fatty acids occurring in $S$. putris nor the composition and biosynthesis of the non-saponifiable lipids will be discussed here, but dealt with in separate papers.

Acknowledgement-The authors wish to thank Professor D. I. Zandee for his interest and critical reading of the manuscript. 


\section{REFERENCES}

Bergmann W. (1962) Sterols: their structure and distribution. In Comparative Biochemistry (Edited by Florkin M. \& Mason S.), Vol. 3, pp. 103-162. Academic Press, New York.

BlIGH E. G. \& DYER W. J. (1959) A rapid method of total lipid extraction and purification. Can. F. Biochem. Physiol. 37, 911-917.

Fagerlund U. H. M. \& IdLer D. R. (1960) Marine sterols--VI. Sterol biosynthesis in molluscs and echinoderms. Can. F. Biochem. Physiol. 38, 997-1002.

Farquhar J. W., Insull W., Jr., Rosen P., Stoffel W. \& Ahrens E. H., Jr. (1959) The analysis of fatty acid mixtures by gas-liquid chromatography. Construction and operation of an ionization chamber instrument. Nutr. Rev. 17, suppl.

GOLdFINE H. \& BLOCH K. (1961) On the origin of unsaturated fatty acids in Clostridia. 7. biol. Chem. 236, 2596-2601.

Gruger E. H., Jr., Nelson R. W. \& Standsby M. E. (1964) Fatty acid composition of oils from 21 species of marine fish, fresh-water fish and shellfish. F. Am. Oil Chem. Soc. 41, 662-667.

Hayes F. N., Rogers B. S. \& Langham W. H. (1956) Counting suspensions in liquid scintillators. Nucleonics 14, 48-51.

Salaque A., Barbier M. \& Lederer E. (1966) Sur la biosynthèse des stérols de l'huître (Ostrea gryphea) et de l'oursin (Paracentrotus lividus). Comp. Biochem. Physiol. 19, $45-51$.

Saxena S. C. \& Zandee D. I. (1968) Fatty acid composition of a fresh-water carp, Scardinius erythrophtalmus L. Archs Int. Physiol. Biochem. 76, 434-440.

SChlenk H. \& Gellerman J. (1960) Esterification of fatty acids with diazomethane on a small scale. Analyt. Chem. 32, 1412-1414.

Venugopalan V. K. (1966) Fatty acid composition of the fat in two sexes of the oyster, Crassostrea madrasensis (Preston). Current Sci. 35, 99.

Voogt P. A. (1967a) Biosynthesis of $3 \beta$-sterols in a snail, Arion rufus L., from $1-{ }^{14} \mathrm{C}-$ acetate. Archs Int. Physiol. Biochem. 75, 492-500.

VoogT P. A. (1967b) Investigations of the capacity of synthesizing $3 \beta$-sterols in MolluscaI. Absence of $3 \beta$-sterol synthesis in a whelk, Buccinum undatum L. Archs Int. Physiol. Biochem. 75, 809-815.

Voogt P. A. (1968a) Investigations of the capacity of synthesizing $3 \beta$-sterols in MolluscaII. Study on the biosynthesis of $3 \beta$-sterols in some representatives of the order Basommatophora. Comp. Biochem. Physiol. 25, 943-948.

VooGT P. A. (1968b) Investigations of the capacity of synthesizing $3 \beta$-sterols in MolluscaIII. The biosynthesis of $3 \beta$-sterols in some archeogastropods. Archs Int. Physiol. Biochem. 76, 721-730.

VoogT P. A. (1969) Investigations of the capacity of synthesizing $3 \beta$-sterols in MolluscaIV. The biosynthesis of $3 \beta$-sterols in some mesogastropods. Comp. Biochem. Physiol. 31, 37-46.

White H. B. (1966) A complementary thin-layer and gas-liquid chromatographic procedure for fatty acid analysis. F. Chromat. 2, 213-222.

White H. B. \& Williams W. L. (1965) Analysis of unsaturated fatty esters as mercurated adducts by thin-layer chromatography. Fedn Proc. 24 (2), 662.

ZaNDEE D. I. (1967) The absence of cholesterol synthesis in Sepia officinalis L. Archs Int. Physiol. Biochem. 75, 487-491.

Key Word Index-Fatty acids in snail; Succinea putris (snail); acetate metabolism; lipid synthesis in snail. 